4

\title{
A Two-Year Life History Cycle Model for Autumn and Spring Seedling Coexistence inan Annual Plant - an Example of Intraspecific Niche Differentiation
}

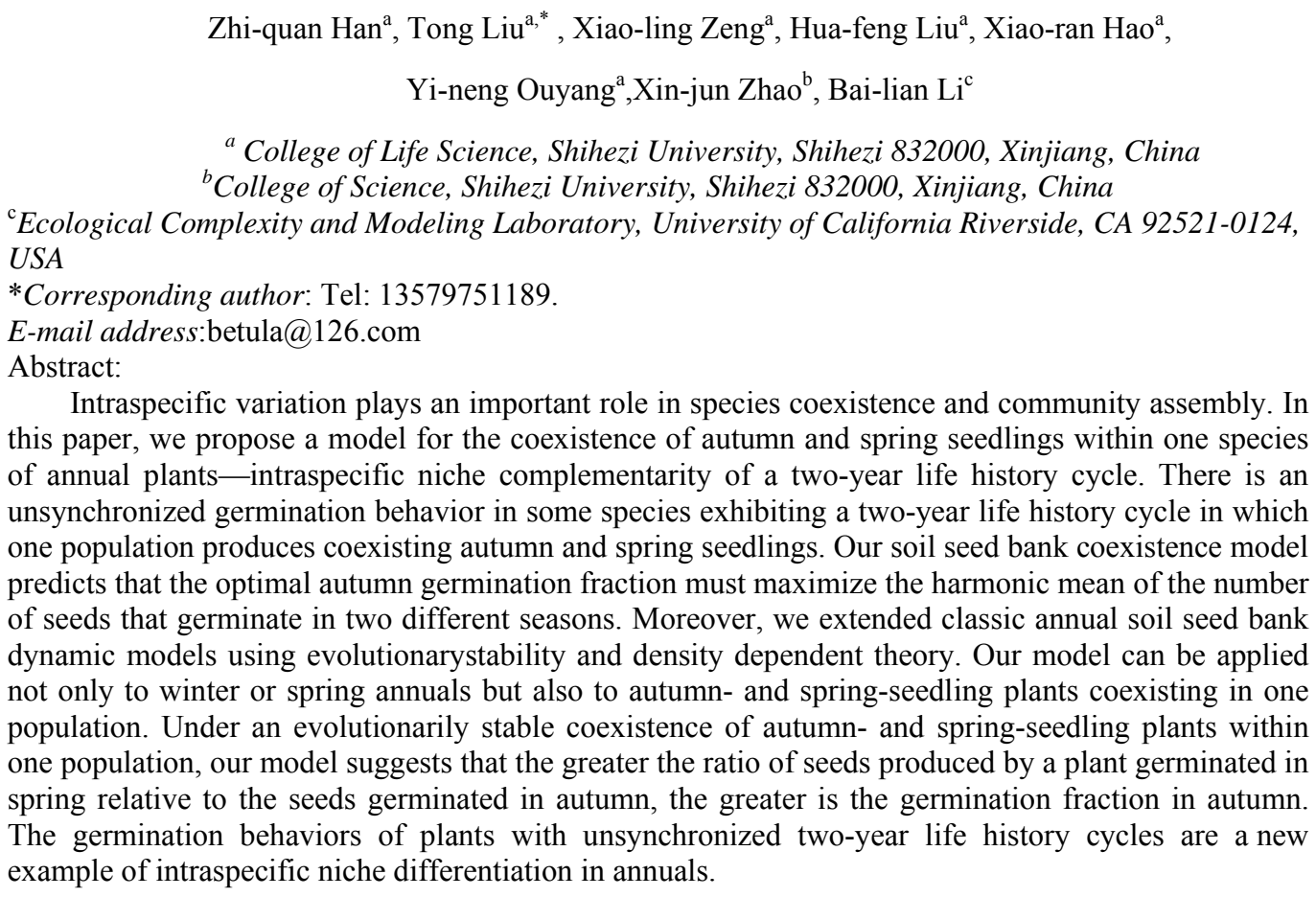

Keywords: seed germination; evolutionary stablecoexistence; life history cycle, germination fraction; Reciprocal Yield Law

\section{INTRODUCTION}

Competition and coexistence of species within communities is a fundamental and current topic of ecological research. Recently, ecologists reconsidered the importance of intraspecific trait variability (Violle et al. 2012), which is important as interspecific trait variability and has significant effects on community assembly. Currently, most research explores intraspecific niche differentiation mainly by individual species with functional trait differences (Bagousse-Pinguet 2014,Albert 2014). However, the role of individual differences caused by unsynchronized life history cycles in intraspecific niche differentiation remains largely unknown.

Life history can be considered a comprehensive reaction to environmental stress. Seed germination timing is a key feature of the plant life cycle because it affects the survival of seedlings (Baskin, 1985), individual fitness, and life history(Masuda and Washitani 1992). Life history differences within individual species can also promote species coexistence (Violle et al, 2012).

We note that most of the population of an annual plant germinates in autumn in one year and in spring in the next. However, in a given year, the same population is composed of autumn-germinating and spring-germinating individuals. In this study, in the two-year life history cycle of annual plants, the change in seed germination time follows a cycle of two years: seeds produced by a spring-germinating plant in the first year germinate largely in autumn of the first year, and seeds produced by an autumn-germinating plant in the first year germinate largely in spring of the second year largely, for a cycle interval of two years. This cycle is different from the classic one-year life history cycle, in which germination time does not change over years (Baskin, 1985) ) (see Figure 1).

Annual plants are an important part of the vegetation in arid and semiarid areas(Ludwig et al, 1988) and, subsequently, have an important impact on the stability and biodiversity of desert ecosystems. Annuals are an ideal system for examining variable response to precipitation and their impact on population and community dynamics (Angert et al, 2009). There are two types of annual plants:1) the winter annuals, including species that germinate during autumn and reproduce during early summer 
and2) the summer annuals, including species that germinate during early spring and complete their life-cycles during summer.

At present, there is substantial evolutionary ecology research focusing on winter annualsbecause of special function in community (Montesinos-Navarro et al 2012,Huxman et al 2013, Gremer and Venable 2014). There are also many theoretical models that describe and predict germination fractions and differences in germination timing (Andrea and Eva 2002, Jessica and Pete2009, Kimball et al 2011, Linkies and Leubner-Metzger 2012, Bessho and Iwasa 2012, Gremer and Venable 2014). However, winter annuals include two groups, obligate winter annuals and facultative winter annuals(Baskin and Baskin 2014). Seeds of obligate winter annuals only germinate during autumn (Cici and Van 2009). Most seeds of facultative winter annuals germinate during autumn; however, some germinate during spring, which results inthe coexistence of autumn and spring seedlings. This type of coexistence is widespread in regions such as the cold deserts andhigh altitude regions.However, a soil seed bank dynamic model for populations in which autumn and spring seedlings coexist has not yet been formulated.

In this paper, we used an evolutionary perspective (see (i) and (ii) of Box 1) to show that a two-year life history cycle allow improves autumn and spring seedling coexistence in populations. To further understand themechanism of evolutionarily stable coexistence andto predict the proportion of seeds with autumn germination,we developed a new soil seed bank dynamic coexistence model using evolutionary stability theory and density dependent theory.

\section{Two Years Life History Cycle for Autumn and Spring Seedling Coexistence within-species}

There are annual species show variable germination time, one of most notable example is Bromus tectorum in Western US (Mack and Pyle 1983). The seeds of some annuals can germinate not only in spring but also in autumn so that there is autumn and spring seedling coexistence in one population (Zhang et al 2007). Also,there are some the species we surveyed in Appendix 1.The site is located in the southern Junggar Basin and in the southern Gurbantunggut Desert, N44 $23^{\prime} 52^{\prime \prime}-\mathrm{N} 45^{\circ} 31^{\prime} 57^{\prime \prime}$ and E84 $54^{\prime} 37^{\prime \prime}-\mathrm{E} 88^{\circ} 50^{\prime} 03^{\prime \prime}$. The altitude is $255-699 \mathrm{~m}$. The climate is temperate arid. Annual evaporation is between 2000 and $2800 \mathrm{~mm}$, and annual precipitation is between 50 and $160 \mathrm{~mm}$. Average snow depth in winter is $10-30 \mathrm{~cm}$ (Zhang and Chen 2002). For the region, with specific reference to the past 50 years,recent climate change researchshowed that autumn was the season when the temperature increased most dramatically, and winter and autumn were the seasons when the precipitation increased most dramatically ( $\mathrm{Xu}$ et al 2014).In an ecological context, knowledge of intraspecificvariation duringdormancy and germination is necessary for both practical and theoretical reasons (Violle et al. 2012). In the present study, we elucidated the theoretical reasonsforvariable germination times.

\section{Please insert Figure 1 about here}

There is life history cycle diversity for annuals. Some species is life cycle of type 1 (Fig.1 A), and some species is life cycle of type 2 (Fig.1 B). For a large number of spring and autumn germinating seedlings co-existence appearing inspring, there are lifecycle of type 3 and type 4 (Fig.1 C and D). For lifecycle of type 4 (Fig.1 D), there are two separate life history patterns within a species, and both of them are one-year life history cycles(Baskin and Baskin 1989). We believe lifecycle of type 3 (Fig.1 C) which is one life history patterns with a two-year life history circle is possible because ofthe evolution of phenotypic plasticity and a long-term niche differentiation.Accordingly, the life history cycle of species cannot be synchronized at the population level such that a fraction of the seeds germinate in autumn (an autumn germination fraction) in one year and two phenotypes subpopulations of seeds are produced in spring that germinate in either spring or autumn. What is the optimal relationship between the two phenotypes subpopulations, or in other words, what is the optimal autumn germination fraction? Accordingly, we examined the coexistence of autumn and spring seedlings using evolutionary stability theory and density dependent theory.

\section{The stable coexistence of autumn- and spring-seedlings.}

We present a soil seed bank model for populations of annuals in which autumn and spring seedling coexist in cold desert. The germination fraction of seed is $g$. Seed germinationin autumn have different fates in winter.Because the seedlings must grow enough before winter to survive over winter, the seed germinated in autumn was divided into two types: winter-successful and winter-dying types. Only winter-successful seedlings will participate in competition the following spring. The fraction ofwinter-successful autumn germination is $g_{f}$. The fraction ofwinter-dying autumn germination is $g_{d}$, which is determined by species and winter temperature but not by density dependence. So $g_{f}+g_{d}$ is not 
affected by spring precipitation. Because there is no mortality from cold temperatures, seeds germinating in spring have only one fate. Thefraction of spring germination is $g_{s}$ which is affected by spring precipitation. So we have the following relationship: $g_{s}+g_{f}+g_{d}=g$.

Variable germination times are is important not only for avoiding the crowds but also making life cycle evolution from one to anotherin unstable weather conditions in cold desert regions. There are many species that can germinate in autumn, not only for some winter annuals but also some spring annuals, but have not been eliminated by natural selection in cold desert. With fluctuating climate,we speculate that the boundaries between winter and spring annual species are not clear, mainlybecause $g_{d}>0$. But Karlsson and Milberg discovered that germination in autumn occurs but plants survive winters poorly for spring annuals and that strong dormancy restricts the portion of each seed batch that germinates each autumn and thus reduces the risk of winter mortality (Karlsson and Milberg 2008). Here, there are some seeds that germinate with bad timing, e.g., before the first snow, so by the definition of $g_{d}, g_{d}>0$, and we expect that $g_{d}$ is constant for a given species.

Please insert Box 1 about here

Cohen analysis of seed banks is a classical theoretical study (Cohen 1966). Ellner improved Cohen's model usinga yield-density law (Ellner1985) that is the "Reciprocal Yield Law" (RYL) first proposed by Shinozaki and Kira (Shinozaki and Kira 1956). The modeltaking into account density dependenceis summarized in the dynamic seed bank model developed(Bulmer1984, Ellner1985)and achieved Eq. (1):

Where $S(t)$ is the number of seed bank in the $t^{t h}$ season $H$ is the average yield of each plant in the $t^{t h}$ season. $g$ is the total germination ratio (germination fraction). dis the death rate of seed dormancy.

$f(x)=Q /(Q+x)(\mathrm{RYL})$ represents the function of density dependence, and $x=g S(t)$ denotes the surviving seeds after germination competition, where $Q$ is the carrying capacity of the system(Bulmer1984, Ellner1985), i.e., the maximum density of adult plants supported by the environment.

In order to investigatethe coexistence of autumn- and spring-germinating seedlingsfromthe evolutionary point of view, wewill present a model describing soil seed bank dynamics of coexisting autumn- and spring-seedling plants based onthe requirements of density dependent evolutionary stability.

After the seedling stage, how is the difference reflected in density dependence? Considering the coexistence of spring and autumn seedlings, the first part of the left-hand side of Eq. (1) must be expanded, and the second part may remain unchanged.

Density-dependence in every phenotype subpopulation follows the Reciprocal Yield Law. When seeds are dispersed, the resources and ecological nicheutilizedby the seed bank are already occupied; therefore, autumn- and spring-germinating seedlings during spring have their own carrying capacity and density restrictions.

Using the Reciprocal Yield Law, we let $y_{f}(t)=Q_{f} g_{f} S(t) /\left(Q_{f}+g_{f} S(t)\right)$ and $y_{s}(t)=$ $Q_{s} g_{s} S(t) /\left(Q_{s}+g_{s} S(t)\right)$, where $y_{f}(t)\left(\right.$ or $\left.y_{s}(t)\right)$ is the number of plants growing from autumn (spring)-germinating seeds without interference from the spring (autumn)-germinating seedlings, and $Q_{f} /\left(Q_{f}+g_{f} S(t)\right)\left(\right.$ or $\left.Q_{s} /\left(Q_{s}+g_{s} S(t)\right)\right)$ consider only intraspecific competition in autumn (spring)-germinating seedlings. $Q_{f}\left(\right.$ or $\left.Q_{s}\right)$ is the number of the autumn (spring)-germinating seedlings of environment permitting.

$F_{s}\left(y_{s}(t), y_{f}(t)\right)\left(\operatorname{or} F_{f}\left(y_{s}(t), y_{f}(t)\right)\right)$ ascompetition limitationprovides the biomass of the spring (autumn) cohort under resource competition between two cohorts,only considering interspecific competition. $Y_{s}(t)=g_{s} S(t)\left(\frac{Q_{s}}{Q_{s}+g_{s} S(t)}\right) F_{s}\left(y_{s}(t), y_{f}(t)\right) H_{s}=y_{s}(t) F_{s}\left(y_{s}(t), y_{f}(t)\right) H_{s}$ or $\left(Y_{f}(t)=\right.$ $\left.g_{f} S(t)\left(\frac{Q_{f}}{Q_{f}+g_{f} S(t)}\right) F_{f}\left(y_{s}(t), y_{f}(t)\right) H_{f}=y_{f}(t) F_{f}\left(y_{s}(t), y_{f}(t)\right) H_{f}\right)$ is the seed production of the spring (autumn) cohort lastly, where $Q_{s} /\left(Q_{s}+g_{s} S(t)\right)$ can be seen as resource competition within the spring cohort, and $F_{s}\left(y_{s}(t), y_{f}(t)\right)\left(\operatorname{or} F_{f}\left(y_{s}(t), y_{f}(t)\right)\right)$ represents resource competition between two cohorts.

Please insert Figure 2 about here

We have a new model from Figure 2 and Box 1:

$$
S(t+1)=\frac{y_{s}(t) y_{f}(t)}{y_{s}(t)+A y_{f}(t)} H_{f}+\frac{y_{f}(t) y_{s}(t)}{y_{f}(t)+a y_{s}(t)} H_{S}+S(t)(1-d)(1-g)(2)
$$


Where $S(t)$ is the number of seed bank in the $t^{t h}$ season; $g$ is the totalgermination fraction; $d$ is the death rate ofdormant seeds; $H_{f}\left(\right.$ or $\left.H_{s}\right)$ is the number of seeds produced by one autumn (spring)-germinated plant. Where $A$, ais constant, which also is relation between autumn-germinating and spring-germinating seedlings.

\section{Results}

For life cycle of type 3 (Fig. $1 \mathrm{C}$ ), it is need to define one important requirement of the optimal autumn germination fraction for a two-year life history cycle permitting the evolutionary coexistence of a population whose individuals germinate in autumn and spring simultaneously in the same year. $Y_{s}(t)=y_{s}(t) F_{s}\left(y_{s}(t), y_{f}(t)\right) H_{s}\left(\operatorname{or} Y_{f}(t)=y_{f}(t) F_{f}\left(y_{s}(t), y_{f}(t)\right) H_{f}\right)$ is seed production of the spring (autumn) cohort lastly. The coexistence of the two phenotypes subpopulations reaches evolutionary stability in long time (see Fig. 3) as $S(t)=S(t+1), Y_{f}(t)=Y_{f}(t+1)$ and $Y_{s}(t)=$ $Y_{S}(t+1)$. When $S(t+1)=S(t)$, as far as possible to avoid the extinction risk from environmental fluctuation, maximizing the number of dormant seeds with no seed deaths $S(t)(1-g)(1-d)=$ $S(t)-\left(Y_{f}(t)+Y_{S}(t)\right)$ (determined by $g_{s}, g_{f}, g_{d}$ and $d\left(g_{d}\right.$ and $d$ were constant in the present paper)) is required, which is equivalent to maximizing $1 /\left(Y_{f}(t)+Y_{s}(t)\right)$. Solving for maximizingthe internal stability strength of the two-year life history cycles according to evolutionary stability is equivalent to maximizing $Y_{s}(t) Y_{f}(t+1)$ and $Y_{f}(t) Y_{s}(t+1) \quad$ (see Fig. 2), which is equivalent to maximizing $Y_{s}(t) Y_{f}(t)$. Therefore, the two subpopulations reaching evolutionary stability over a long time must maximize $Y_{s}(t) Y_{f}(t) /\left(Y_{s}(t)+Y_{f}(t)\right)$.

\section{Please insert Figure 3 about here}

When $Y_{s}(t)+Y_{f}(t)$ is unchanged in the ideal case of evolutionary stability for a seed bank, $Y_{s}(t) Y_{f}(t)$ is maximized when $Y_{s}(t)=Y_{f}(t)$, but the optimal relationship between the two phenotypes subpopulations cannot be solely determined from this information describing soil seed bank dynamics and trends in the germination fraction. So the descriptions of these new soil seed bank dynamics of autumn- and spring-seedling plants coexisting in one species need use evolutionary stability and the density dependent theory.

For a two-year life history cycle to result in coexistence between autumn- and spring-germinating seedlings, and for an evolutionary stable selection of germination timing, the condition is $Y_{s}(t)=$ $Y_{f}(t)$. Therefore, when coexisting populations reach evolutionary stability, we have $A=1 / a=H_{f} / H_{s}$.

Combining the above information, we have

Where $Y_{z}(t)$ is the number of seeds producedby allseedlings,

$$
S(t+1)=Y_{z}(t)+S(t)(1-d)(1-g)(3)
$$

$$
Y_{z}=2 y_{s}(t) y_{f}(t) H_{s} H_{f} /\left(y_{s}(t) H_{s}+y_{f}(t) H_{f}\right)
$$

It is reasonable that RYL is selected as a density-dependence lawin Eq. (1) from economical points of view (Han et al 2014).

Eq. (3) also can be rewritten as

$$
S(t+1)=\frac{Q_{z}}{Q_{z}+\left(g-g_{d}\right) S(t)}\left(g-g_{d}\right) S(t) H_{z}+S(t)(1-d)(1-g)
$$

Where $Q_{z}=\left(\frac{2 H_{s} H_{f} Q_{s} Q_{f}}{H_{s} Q_{s}+H_{f} Q_{f}}\right) /\left(\frac{2 H_{f} H_{s}\left(g-g_{f}-g_{d}\right) g_{f}}{\left(H_{s}\left(g-g_{f}-g_{d}\right)+g_{f} H_{f}\right)\left(g-g_{d}\right)}\right), H_{z}=\frac{2 H_{f} H_{s}\left(g-g_{f}-g_{d}\right) g_{f} /\left(g-g_{d}\right)^{2}}{H_{s}\left(g-g_{f}-g_{d}\right) /\left(g-g_{d}\right)+g_{f} H_{f} /\left(g-g_{d}\right)}$

$Q_{z}$ is the carrying capacity of the system. $H_{z}$ is the number of seeds produced by springand autumn

germinating adult plants.

For Eq.(3),when the total carrying capacity $Q$ is determined by the position and size occupiedbyseeds in soil and autumn and spring -germinating seedlings in spring, Approximatively, in the case $Q_{s}=Q g_{s} /\left(g-g_{d}\right), Q_{f}=Q g_{f} /\left(g-g_{d}\right)$,so $Q_{z}=Q$ (from definition of $\left.Q_{z}\right)$. In this case, when $H_{z}$ is maximum, $Y_{z}$ is maximum. Thus, for Eq.(3) deriving $g_{f}$ is $\operatorname{maximizing} H_{z}$, we have

$$
\frac{g_{f}+g_{d}}{g-g_{d}}=\frac{\sqrt{v}}{\sqrt{v}+1}+\frac{g_{d}}{g-g_{d}}(5)
$$


Where $v=H_{s} / H_{f}$. Without loss of generality, let $g_{d}=0$, we have Fig.4.

Please insert Figure 4 about here

From Fig.4, we can see that the strategy of autumn species in population level is "the greater the fitness advantages of spring seedling, the larger the proportion of autumn germination."'In other words, the greater the ratio of seeds produced by a plant germinated in autumn relative to the seeds germinated in spring, the smaller is the germination fraction in autumn.

Equation 2 can be applied not only to autumn-germinating and spring-germinating plants coexisting in one species for life-cycle of type 3 (Fig. 1C) but also other life-cycles.

(i) when $A=0, a=+\infty$,we have $\mathrm{S}(t+1)=Q_{f} g_{f} \mathrm{~S}(t) /\left(Q_{f}+g_{f} \mathrm{~S}(t)\right)+\mathrm{S}(t)(1-d)(1-g)$, and $g_{f} \approx g$ should be best in this case. The species is almost entirely autumn-germinating; namely, a winter annual species (Fig. $1 \mathrm{~A}$ ).

(ii)Or when $A=+\infty, a=0$, we have $\mathrm{S}(t+1)=Q_{s} g_{s} \mathrm{~S}(t) /\left(Q_{s}+g_{s} \mathrm{~S}(t)\right)+\mathrm{S}(t)(1-\mathrm{d})(1-g), g_{s} \approx g$ should be best in this case, the species is almost entirely spring-germinating; namely, a spring annual species(Fig. 1 B).

For both (i) and (ii) there are many studies (Venable 2007, Childs2010, Gremer and Venable 2014). Here we do not discuss further (see Fig.1.A and B).

(iii) $A=0$ and $a=0$, there is no relationship between two cohorts ofautumn-germinating and spring-germinating plants. From Eq. (2) we have

$\mathrm{S}(t+1)=Q_{s} g_{s} S(t) H_{s} /\left(Q_{s}+g_{s} S(t)\right)+Q_{f} g_{f} S(t) H_{f} /\left(Q_{f}+g_{f} S(t)\right)+\mathrm{S}(t)(1-d)(1-g)$

In this case, autumn-germinated plants and spring-germinated plants germinated almost independently of each other. If the growing season of autumn-germinated plants and spring-germinated plantswere staggered, or seeds germinated in autumn stayed together, and seeds germinated in spring stayed together,so that autumn and spring-germinating seedlings in the spring do not interact in resource competition. For example, when spring arrives, autumn-germinating seedlings are taller and have deeper roots than spring-germinating seedlings. Thus, the two subpopulations occupy different ecological niches, and their competition with each other can be ignored. Further, when autumn-germinating seedlings mature, their competition with each other can be ignoredsuch that there is always no competition between the two subpopulations.From Equation 6, it is evidentthat "the greater the fitness advantage of the spring seedlings, the larger the proportion of spring germination." In this case, the two genotypesubpopulations can be considered to betwo cases of the classic one year lifehistory cycles or two separate populations (see Fig. 1D) as the evolution of phenotypic plasticity.

\section{Discussions}

Please insert Figure 5 about here

Equation 3-5 examines competition only within genotypes and between two phenotype populations for life-cycle 3 (Fig. 1C). Equation 5 is deduced based on Equation 4 for the autumn germination fraction in evolutionary stability. Equation 4 shows that when the life-cycle of type 3 reached evolutionary stability, its soil seed bank dynamics model was consistent to the models of classic life-cycle 1 and 2 in form. Life-cycle of type 1, 2 (classic(see Fig. 1A, B)), 3 (Eq. 3, 4(see Fig. 1C)), and 4 (Eq. 6(see Fig. 1D)) can be observed from Figure 5.

We believe that germination withinthe life-cycle ofcertain annuals was simple; for example,certain species always germinate during autumn or spring, whereas others may have a mixed life-history with varying focus. Nevertheless, Equation 2 can be used to describe them (see Fig. 5). There are several studies regarding the life-cycle of type 1, 2 (Bulmer1984, Ellner1985, Gremer and Venable 2014), and here, we focus on the life-cycle of type 3 and 4, particularlythe life-cycle of type 3. From Figure 4, it is evident that the strategy of choice for life-history phenotypic differentiation at a population level which is "the greater the fitness advantages of spring seedling, the larger the proportion of autumn germination."

As an early life-history trait, germinationphenology can be critical in determining the fate of the organism because plasticity can synchronize the most vulnerable life-history stages with favorable environmental windows(Forrest2010, Montesinos-Navarroet al 2012) and is influenced by strong natural selection(Donohue et al. 2005). There is a rich differentiation between species and within species (Barua2012,Montesinos-Navarro et al 2012, Basin et al. 2014), even among populations(Fernández-Pascual et al2013). Variousfactors affect seed germination and dormancy, including species genetics, the seed maturation process, and environment experience, particularly the maternal environment affects the genetic basis of seed dormancy (Postmaand Agren2015). 
From our observations, the phenology of autumn germinating plants are earlier than spring germinating plants, such that two cohorts experience significantly different temperatures,photoperiod, and moisture during seed maturation and development,which strongly influenceprimary dormancy induction (and breakage), secondary dormancy induction (and breakage), and the conditions that permit the germination of non-dormant seeds(Donohue 2009). Seeds matured under long, warm days exhibited greater germination than those matured under short, warm days(Barua et al. 2012). The spring germinating plantsexperienced longer warm daysthan autumn germinating plants, whose seeds can germinate during autumn when germination conditions were satisfied.The maternal environment during seed maturation affects seed dormancy and consequently seed longevity. With downy brome, for example, if the seed maturation period is prolonged the seed dormancy period increases (Allen and Meyer 2002). Similarly, for cleavers, Mennan and Ngouajio (2006) reported that seeds from fallemergingcohortsgerminated more quickly than seeds from spring-emerging cohorts.

Meanwhile, the seed coat (testa)can be a physical constraint on dormancy and germination because of mediatingseed water permeability and/or oxygen uptake and the light environment experienced by the embryo. Plants were from autumn germinating seedlings, and experienced autumn, winter, and spring with a long growing season and more available resources; therefore, they produced more seeds during summer(Appendix 1, Table 2), and most of the seeds had full, thickertesta than spring germinating seedlings. Although germination conditions were met during autumn, most of these seeds did not easily germinate and germinatedthe following spring.However, the autumn-germinating plants hada larger biomass and more than twice the seed yield of spring-germinating plants in the present study. There is a negative correlation between the number of offspring produced and germination rate (TielbörgerandPetru2010). Therefore, the dormancy of seeds produced by spring annuals is generally less than that of seeds produced by winter annuals when undergoing suitable temperature and moisture conditions. For the above and other reasons, the life-cycle of type 3(twoyear life-history cycle) was inevitable emergence.

Seed germinationis often controlled by the existence of dormancy cycles and occurs at the right time of the season to provide the best chance for plant development, particularly in arid and semiarid climates.Hence,the formation of the seed dormancy cycle is because of the combined action between seed annual dormancyinduction (and breakage) and post-germination traits(Baskin et al 1993,Donohueet al 2010, Caoet al 2013, Montesinos-Navarro et al 2012). The post-germination traits regulate interspecific interactions, intraspecific density dependence, and inorganic environment stress and react to germination time(TielbörgerandValleriani 2005, Gremerand Venable 2014). Selection could favor divergence of the seasonal cue level that triggers a life-cycle transition, resulting in stable coexistence of phenological polymorphisms within a population or the potential for multiple phenological responses associated with a single genotype(Metcalfet al 2015). In the present study, life-history 3 and life-history 4were evident, which haveobvious advantagesforstable coexistence within a population. Possessionof life-history 3 and life-history 4 mainly varies with the species, population, and local environment. A twoyear life-history cycleis advantageousfor post-germination traits and should existunder naturalconditions.

In recent years, there has been a rapid increase in the number of published reports of intraspecific variability in plant ecology (Albert 2014). Our theory regarding germination behavior within a two-year life history cycle in one population provides a new example of intraspecific niche differentiation in plants. A two-year life history cycle provides more niche space than a one-year life history cycle because the seed germination times of winter and spring annuals are not synchronized in one population. Life history strategy is one of the most important sources of intraspecific niche differentiation caused by individual differences (Zuppinger-Dingley et al 2014) and should therefore receive more attention in plant community ecology theory. Therefore, we can expect that intraspecific niche differentiation produced by life history cycles to have significant effects on community assembly and coexistence.

It is difficult to describe the interaction between two populations in coexistence theory. The interaction between the two phenology subpopulations is unchanged whether they are achieved evolutionary stable coexistence or not, so with the requirements of the evolutionary stability, we can get more information about the interaction between the two populations.For understanding the effect oftwo year life history on evolution, we extended previous annual soil seed bank dynamics models (Bulmer 1984, Gremer and Venable 2014) based on requirements of evolutionary stability and density-dependence. Our model can be applied not only to winter or spring annuals but also to autumn-seedling and spring-seedling plants coexisting in one population. Our model quantified the evolution of autumn germination, which to our knowledge has never been done in the previous literature.

Acknowledgements: The research presented in this paper is supported by the National Science Foundation of China (Grant No. 41061004),Joint Fund of NSFC-Xinjiang (Grant No. U1130304), the 
372 Cao D.C., Baskin C.C., Baskin J.M., Yang F., Huang Z.Y. 2014 Dormancy cycling persistence of seeds 373 in soil of a cold desert halophyte shrub. Annals of Botany, 113, 171-179.

374 César Cendán, Luis Sampedro, Rafael Zas. 2013The maternal environment determines the timing of 375 germination in Pinuspinaster. Environmental and Experimental Botany 94: 66-72.

376 Childs, D. Z., Metcalf, C. J. E., Rees, M., 2010 Evolutionary bet-hedging in the real world: empirical 377 evidence and challenges revealed by plants. Proceedings of the Royal Society B: Biological Sciences. 378 277(1697): 3055-3064.

379 Cohen, D., 1966 Optimizing reproduction in a randomly varying environment. Journal of Theoretical 380 Biology 12(1): 119-129. 
410 Huxman, T. E., Kimball, S., Angert, A. L., Gremer, J. R., Barron-Gafford, G. A., \& Venable, D.

411 L., 2013 Understanding past, contemporary, and future dynamics of plants, populations, and 412 communities using Sonoran Desert winter annuals. American journal of botany 100(7): 1369-1380.

413 Jessica, J. K., Peter, C., 2009 Coexistence of annual plants: generalist seed predation weakens the 414 storage effect. Ecology 90(1): 170-182.

415 Karlsson, L.M., Milberg, P. 2008. Variation within species and inter-species comparison of seed 416 dormancy and germination of four annual Lamium species. Flora 203: 409-420.

417 Kimball, S., Angert, A. L., Huxman, T. E., Venable, D. L., 2011 Differences in the timing of 418 germination and reproduction relate to growth physiology and population dynamics of Sonoran Desert 419 winter annuals. American Journal of Botany 98(11): 1773-1781.

420 GehanJayasuriya, K.M.G., Yasoja, S.,Athugala,et al. 2015 Annual dormancy cycles in buried seeds of 421 shrub species: germination ecology of Sideritisserrata (Labiatae). Plant Biology, 17, 798-807.

422 Linkies, A., Leubner-Metzger, G., 2012. Beyond gibberellins and abscisic acid: how ethylene and 423 jasmonates control seed germination. Plant cell reports 31(2): 253-270. 
424 Ludwig,J.A.,Cunningham,G.L., Whitson, P.D.,1988Distribution of annual plants in north American

425 deserts. Journal arid of environments 15:221-227.

426 Mack, R. N., Pyke, D. A. 1983The demography of Bromus tectorum: variation in time and space[J].

427 The Journal of Ecology, 71, 69-93.

428 Masuda, M., Washitani, I., 1992 Differentiation of spring emerging and autumn emerging ecotypes in

429 Galiumspurium L. var. echinospermon. Oecologia 89(1): 42-46.

430 Mayfield, M.M., Dwyer, J.M, Main, A., et al., 2014The germination strategies of widespread annual

431 plants are unrelated to regional climate. Global Ecology and Biogeography 23(12): 1430-1439.

432

433

434

435

436

437

438

439

440

441

442

443

444

Metcalf, C.J.E., Burghardt, L.T.,\&Koons, D.N. 2015 Avoiding the crowds: the evolution of plastic

responses to seasonal cues in a density - dependent world. Journal of Ecology,103(4), 819-828.

\section{Montesinos-Navarro, A.F.,Picó, X., Tonsor, S.J. 2012Clinal variation in seedtraits influencing life cycle timing in Arabidopsis thaliana. Evolution, 66(11), 3417-3431.}

Nandula, V. K., Eubank, T. W., Poston, D. H., Koger, C. H. and Reddy, K. N. 2006 Factors affecting germination of horseweed (Conyzacanadensis). Weed Sci. 54: 898-902.

\section{Postma, F. M., Ågren, J. 2015 Maternal environment affects the genetic basis of seed dormancy in} Arabidopsis thaliana.Molecular Ecology, 24, 785-797.

Shinozaki, k., Kira, T., 1956 Intraspecificcompetion among higher plants.VII. Logistic theory of the C-D effect. Journal of the Institute of Polytechnics, Osaka City University, Series D. 7: 35-72.

Stearns, S. C., 1992 The Evolution of Life Histories. Oxford Univ. Press, New York.

\section{Tielbörger, K. \& Valleriani, A. 2005Can seeds predict their future? Germination strategies of density-regulated desert annuals.Oikos, 111, 235-244.}

Tielbörger, K., Petrů, M., 2010.An experimental test for effects of the maternal environment on delayed germination. Journal of Ecology 98(5): 1216-1223.

Venable, D. L., 2007. Bet hedging in a guild of desert annuals. Ecology 88(5): 1086-1090.

Violle, C., Enquist, B. J., McGill, B. J., Jiang, L., Albert, C. H., Hulshof, C., Jung, V., Messier, J. 2012 The return of the variance: intraspecific variability in community ecology. Trends in Ecology \& Evolution7(4): 244-252.

Willis, C.G., Baskin, C.C., Baskin, J.M., et al., 2014 The evolution of seed dormancy: environmental cues, evolutionary hubs, and diversification of the seed plants. New Phytologist, 203(1): 300-309.

$\mathrm{Xu} \mathrm{C,} \mathrm{Li} \mathrm{J,} \mathrm{Zhao} \mathrm{J,} \mathrm{et} \mathrm{al.} \mathrm{2014Climate} \mathrm{variations} \mathrm{in} \mathrm{northern} \mathrm{Xinjiang} \mathrm{of} \mathrm{China} \mathrm{over} \mathrm{the} \mathrm{past} 50$ years under global warming. Quaternary International 358(9): 83-92.

Zeng, X.L., Liu, T., Shen, X. Y., Niu, P.X., 2011. Environment dependence of seed germination in autumn in GrurbantonggutDesert.Chinese Journal of Ecology 30(8): 1-8.

Zhang, L.Y., Chen, C.D., 2002 On the General Characteristics of Plant diversity of Gurbantunggut Sandy Desert.ActaEcologicaSinica 22(11): 1923-1932.

Zhang, T., Sun, Y., Tian, C.Y., Feng, G., 2007. Ecological and Biological Differences between Spring and Autumn Plants of Two Desert Ephemerals. Journal of Plant Ecology 31(6): 1174-1180.

Zuppinger-Dingley, D., Schmid, B., Petermann, J. S., Yadav, V., De Deyn, G. B., Flynn, D. F. B. 2014. Selection for niche differentiation in plant communities increases biodiversity effects. Nature 515(7525): 108-111. 
471

472

473

474

475

476

477

478

479

480

481

482

483

484

485

486

487

488

489

490

491

492

493

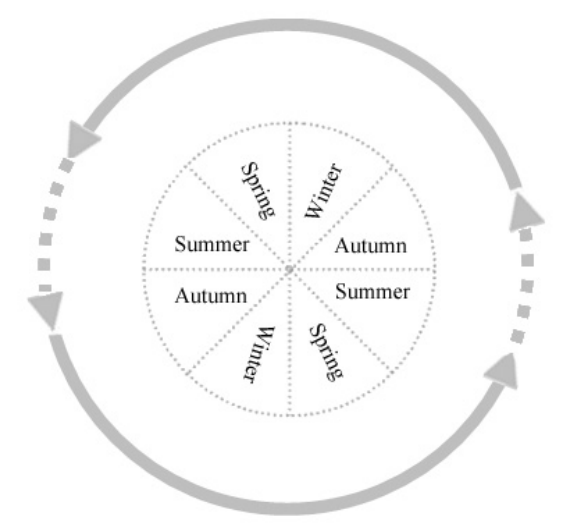

A: Winter annuals

Seeds germinate in autumn and plants reproduce in the spring, which is a one-year life history cycle. Seedlings need to survive in winter.

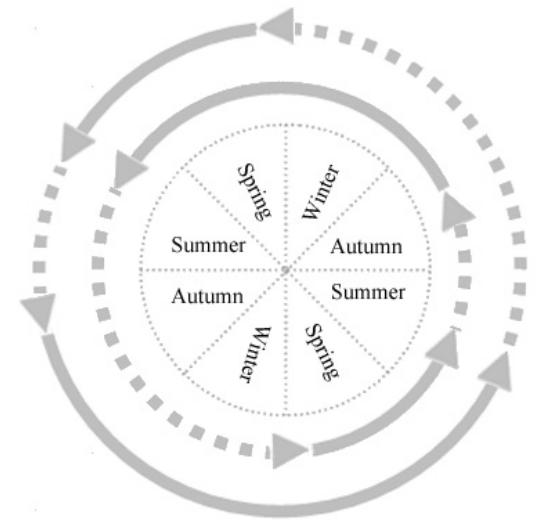

C: Coexistence with two years life history circle There is one life history patterns with a two-year life history circle. Different seed germination times result in the autumn and spring seedling coexistence.

Plant stage

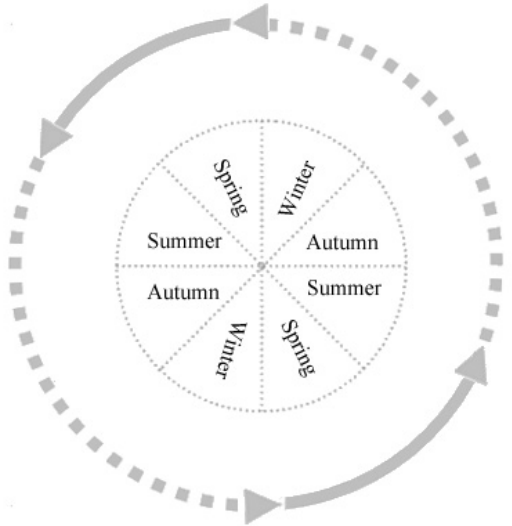

B: Spring annuals

Seeds germinate in spring and plants reproduce in the summer, which is a one-year life history cycle.

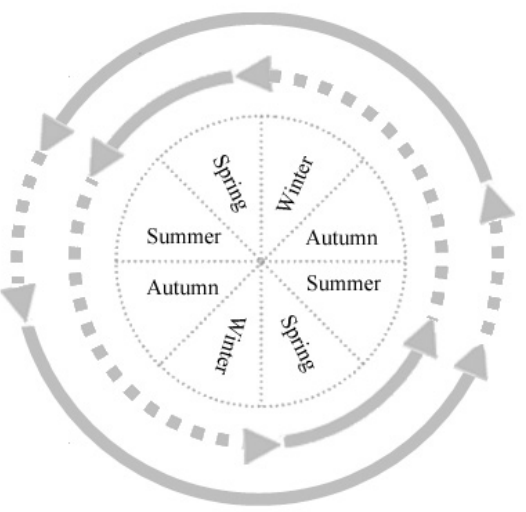

D: Coexistence by mixing with two life history patterns There are two separate life history patterns within a species, and both of them are one-year life history cycles such that there is autumn and spring plants coexistence in one population.

Seed stage

Fig.1. the different life history cycles of annuals and the different niche characteristics permitting coexistence within one population in long time. 


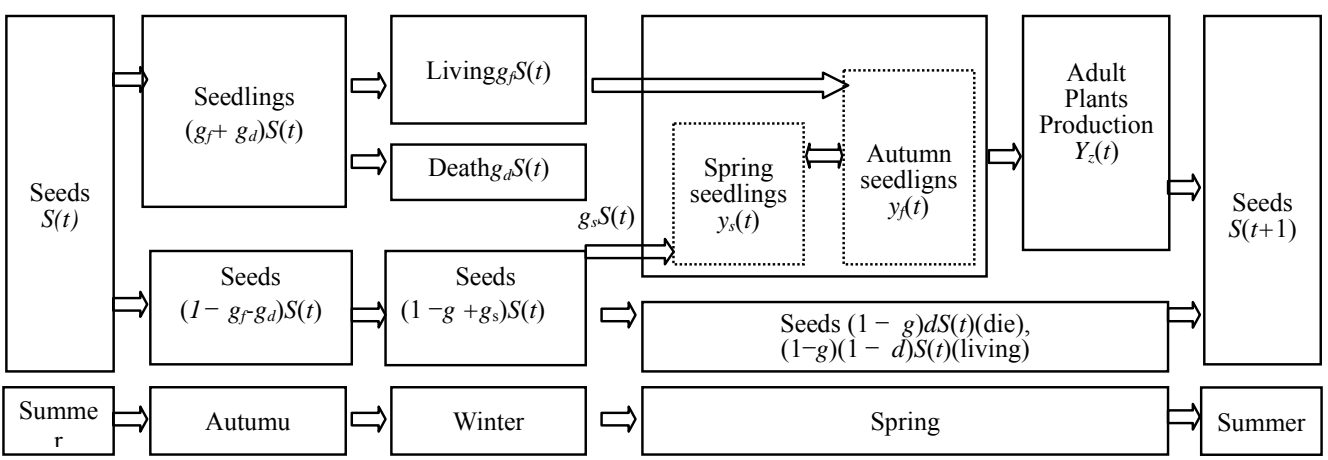

506

Fig.2. Different germination timing produces different fate and life history variation in annuals.

Where $S(t)$ is the number of seed bank in the $t^{\text {th }}$ season; gis the total germination ratio (germination fraction); $\boldsymbol{d}$ isthe death rate of dormant seeds; The fraction ofwinter-successful autumn germination is $\boldsymbol{g}_{\boldsymbol{f}}$. The fraction ofwinter-dying autumn germination is $\boldsymbol{g}_{\boldsymbol{d}}$, which is determined by species and winter temperature but not by density dependence; the fraction of spring germination is $\boldsymbol{g}_{s}$ affected by spring precipitation. $y_{f}(t)$ is the number of plants from autumn-germinating seeds without interference from the spring-germinating seedlings. $\boldsymbol{y}_{\boldsymbol{s}}(\boldsymbol{t})$ is the number of plants from spring-germinating seeds without interference from the autumn-germinated seedlings; $\boldsymbol{Y}_{z}(\boldsymbol{t})$ is the number of seeds produced by all germinating seed in the comprehensive case(the seeds produced by both spring and autumn germinating plants).

\begin{tabular}{|c|c|c|c|}
\hline $\begin{array}{l}\text { Spring-germinating } \\
\text { plants }\end{array}$ & $\begin{array}{l}\text { Seeds reproduced by } \\
\text { spring-germinating plant } Y_{S}(t)\end{array}$ & $\begin{array}{l}\text { Autumn-germinating } \\
\text { plants }\end{array}$ & $\begin{array}{l}\text { Seeds reproduced by autumn } \\
\text {-germinating plant } Y_{f}(t+1)\end{array}$ \\
\hline $\begin{array}{l}\text { Autumn-germinating } \\
\text { plants }\end{array}$ & $\begin{array}{l}\text { Seeds reproduced by autumn } \\
\text {-germinating plant } Y_{f}(t)\end{array}$ & $\begin{array}{l}\text { Spring-germinating } \\
\text { plants }\end{array}$ & $\begin{array}{l}\text { Seeds reproduced by spring } \\
\text {-germinating plant } Y_{S}(t+1)\end{array}$ \\
\hline
\end{tabular}

Fig. 3. The two years life history cycle in one population of annuals

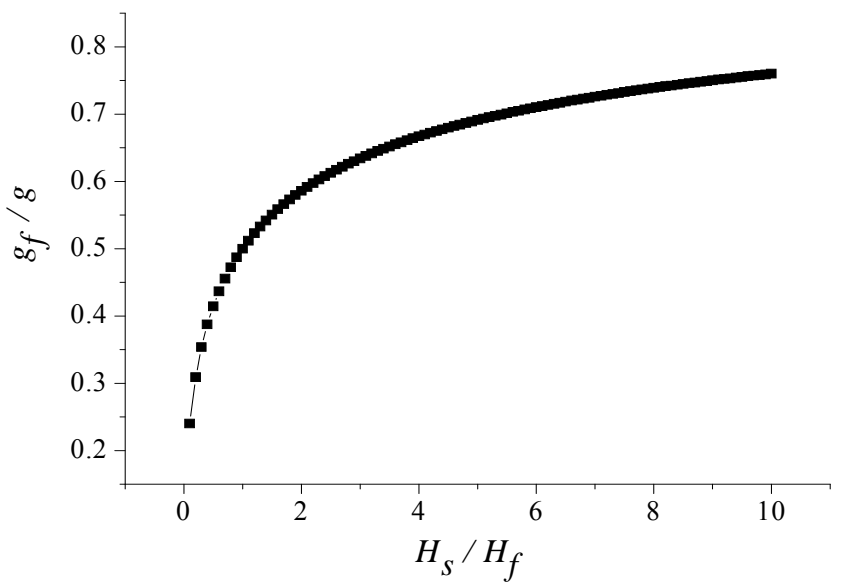

Fig.4. The relationship of the proportion of autumn germination in total germination (germination fraction) $g_{f} / g$ and the ratio between plants produced during spring and autumn germination $v=H_{s} / H_{f}$. 


\begin{tabular}{|c|c|c|}
\hline \multirow{2}{*}{$Y_{z}(t)=\frac{y_{s}(t) y_{f}(t) H_{f}}{y_{s}(t)+A y_{f}(t)}+\frac{y_{f}(t) y_{s}(t) H_{s}}{y_{f}(t)+a y_{s}(t)}$} & Spring seedlings & $\begin{array}{l}\text { Seeds reproduced } \\
\text { by spring seedling }\end{array}$ \\
\hline & Autumn seedlings & $\begin{array}{l}\text { Seeds reproduced } \\
\text { by autumn seedling }\end{array}$ \\
\hline$a \rightarrow+\infty, A \rightarrow 0, Y_{z}(t)=\frac{Q_{f} g_{f} S(t)}{Q_{f}+g_{f} S(t)} H_{f}$ & Autumn seedlings & $\begin{array}{l}\text { Seeds reproduced } \\
\text { by autumn seedling }\end{array}$ \\
\hline$a \rightarrow 0, A \rightarrow+\infty, Y_{z}(t)=\frac{Q_{s} g_{s} S(t)}{Q_{s}+g_{s} S(t)} H_{s}$ & Spring seedlings & $\begin{array}{l}\text { Seeds reproduced } \\
\text { by spring seedling }\end{array}$ \\
\hline \multirow{2}{*}{$\begin{array}{l}a \rightarrow 0, A \rightarrow 0, \\
Y_{z}(t)=\frac{Q_{s} g_{s} S(t)}{Q_{s}+g_{s} S(t)} H_{s}+\frac{Q_{f} g_{f} S(t)}{Q_{f}+g_{f} S(t)} H_{f}\end{array}$} & Spring seedlings & $\begin{array}{l}\text { Seed reproduced by } \\
\text { spring seedling }\end{array}$ \\
\hline & Autumn seedlings & $\begin{array}{l}\text { Seeds reproduced } \\
\text { by autumn seedling }\end{array}$ \\
\hline \multirow{2}{*}{$\begin{aligned} A & =1 / a=\frac{H_{f}}{H_{s}} \\
Y_{z} & =\frac{2 y_{s}(t) y_{f}(t)}{y_{s}(t)+y_{f}(t)} H_{f} H_{s}\end{aligned}$} & Spring seedling & $\begin{array}{l}\text { Seeds reproduced } \\
\text { by spring seedling }\end{array}$ \\
\hline & Autumn seedlings & $\begin{array}{l}\text { Seeds reproduced } \\
\text { by autumn seedling }\end{array}$ \\
\hline
\end{tabular}

517 Fig.5. There are different life history cycles in annuals and different soil dynamic models because $Y_{z}(t)$ 518 may differ according 
Box.1 the stable coexistence of the two cohorts

We generally consider a mixed coexistence region over a long period. There are autumn and spring cohorts competition within and among each other. In this paper, $y_{f}(t)$ (or $\left.y_{s}(t)\right)$, simply written as $y_{f}\left(\right.$ or $\left.y_{s}\right)$ in this box, is the number of plants from autumn (spring)-germinating seedlings without interference from the spring(autumn)-germinating seedlings, which are following "Reciprocal Yield Law". $y_{f}(t)=Q_{f} g_{f} S(t) /\left(Q_{f}+g_{f} S(t)\right)$ and $y_{s}(t)=Q_{s} g_{s} S(t) /\left(Q_{s}+g_{s} S(t)\right), g_{f}$ is the fraction of winter-successful autumn germination, $g_{s}$ is the fraction of spring germination, $Q_{f}$ (or $Q_{s}$ ) is the number of the autumn (spring)-germinating seedlings of environment permitting.

There are competitions between autumn and spring cohorts of plants. Let $F_{s}\left(y_{s}(t), y_{f}(t)\right)$ and $F_{f}\left(y_{s}(t), y_{f}(t)\right)$ be competitive limitation of autumn and spring cohorts competition among them. We hypothesize that if there is a slight increase in total precipitation in spring, each germination ways is simultaneously increased by $\mathrm{k}$ times (with $\mathrm{k}$ not very large), the total revenue must also increase ktimes. Thus, we have $F_{s}\left(k y_{s}, k y_{f}\right) k y_{s}=F_{s}\left(y_{s}, y_{f}\right) k y_{s}$ and $F_{f}\left(k y_{s}, k y_{f}\right)=$ $F_{f}\left(y_{s}, y_{f}\right) k y_{f}$. When the number of one type of seedlings is very small because of some occasional interference, the restriction of that cohort of seedlings by the other type will be small because of their own ecological niche. Thus, we have $F_{s}(1, y f) \approx 1$ (when $\left.1 \ll y_{\mathrm{f}}\right)$ and $F_{f}(y s, 1) \approx 1\left(\right.$ when $\left.1 \ll y_{s}\right), \lim _{y_{f} \rightarrow 0} F_{f}\left(y_{s}, y_{f}\right)=1, \lim _{y_{s} \rightarrow 0} F_{s}\left(y_{s}, y_{f}\right)=1$.

(ii) Generally we can let $F_{f}\left(y_{s}, y_{f}\right)=y_{s} /\left(y_{s}+A_{1} y_{f}+\alpha_{1}\left(y_{s}, y_{f}\right)\right)$ and $F_{s}\left(y_{s}, y_{f}\right)=y_{f} /\left(a_{1} y_{s}+y_{f}+\alpha_{2}\left(y_{s}, y_{f}\right)\right)$, where

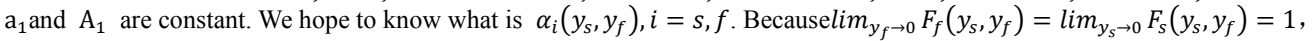
$F_{i}\left(k y_{s}, k y_{f}\right)=F_{i}\left(y_{s}, y_{f}\right), \alpha_{i}\left(y_{s}, y_{f}\right)=\sum e_{i, j} y_{s}^{k_{i, j}} y_{f}^{1-k_{i, j}},(i=s, f)$. Because $F_{s}\left(1, y_{f}\right) \approx 1$ (when $\left.1 \ll y_{f}\right)$ and $F_{f}\left(y_{s}, 1\right) \approx$ 1 when $\left(1 \ll y_{s}\right), A_{1} \ll y_{s}, \alpha_{1}\left(y_{s}, 1\right)=\sum e_{1, j}\left(y_{s}\right)^{k_{1, j}} \ll y_{s}$ so $e_{1, j}\left(y_{s}\right)^{k_{1, j}} \ll y_{s}$ when $\left(1 \ll y_{s}\right)$ and $a_{1} \ll y_{f}, \alpha_{2}\left(1, y_{f}\right)=$ $\sum e_{2, j}\left(y_{f}\right)^{1-k_{2, j}} \ll y_{f}$ so $e_{2, j}\left(y_{f}\right)^{1-k_{2, j}} \ll y_{f}$ when $\left(1 \ll y_{f}\right)$.

So fore $e_{1, j}\left(y_{s}\right)^{k_{1, j}}$, there are $e_{1, j} \approx 0 \quad$ or $k_{1, j} \approx 0$ so that $y_{s}^{k_{1, j}} y_{f}^{1-k_{1, j}} \approx y_{f}$ and $\sum e_{1, j} y_{s}^{k_{1, j}} y_{f}^{1-k_{1, j}} \approx c_{1} y_{f}\left(c_{1} \ll y_{s}\right.$ when $\left.1 \ll y_{s}\right)$, and fore $e_{2, j}\left(y_{f}\right)^{1-k_{2, j}}, e_{2, j} \approx 0$ or $1-k_{2, j} \approx 1$ so that $y_{s}^{k_{2, j}} y_{f}^{1-k_{2, j}} \approx y_{s}$ and $\sum e_{2, j} y_{s}^{k_{2, j}} y_{f}^{1-k_{2, j}} \approx c_{2} y_{s}\left(c_{2} \ll y_{f}\right.$ when $1 \ll y_{f}$ ).

So $A_{1} y_{f}+\alpha_{1}\left(y_{s}, y_{f}\right) \approx A y_{f}, a_{1} y_{s}+\alpha_{2}\left(y_{s}, y_{f}\right) \approx a y_{s}$, where A, a is constant, which also can be seen as relations betweenautumn-germinating and spring-germinating plants.And so $F_{f}\left(y_{s}, y_{f}\right) \approx y_{s} /\left(y_{s}+A y_{f}\right)$ and $F_{s}\left(y_{s}, y_{f}\right) \approx y_{f} /\left(a y_{s}+y_{f}\right)$.So

$$
S(t+1)=\frac{y_{s}(t) y_{f}(t)}{y_{s}(t)+A y_{f}(t)} H_{f}+\frac{y_{f}(t) y_{s}(t)}{y_{f}(t)+a y_{s}(t)} H_{s}+S(t)(1-d)(1-g)
$$

Where $S(t)$ is the number of seed bank in the $t^{t h}$ season; $g$ is the total germination fraction; $d$ is the death rate of dormant seeds; $H_{f}\left(\right.$ or $\left.H_{s}\right)$ is the number of seeds produced by one autumn (spring)-germinated plant. 
543 The site is located in the southern Junggar Basin and in the southern Gurbantunggut Desert, $544 \mathrm{~N}^{\circ} 4^{\circ} 3^{\prime} 52^{\prime \prime}-\mathrm{N} 45^{\circ} 31^{\prime} 57^{\prime \prime}$ and E84 $54^{\prime} 37^{\prime \prime}-\mathrm{E} 88^{\circ} 50^{\prime} 03^{\prime \prime}$. The altitude is $255-699 \mathrm{~m}$. The climate is 545 temperate arid. Annual evaporation is between 2000 and $2800 \mathrm{~mm}$, and annual precipitation is between

54650 and $160 \mathrm{~mm}$. Average snow depth in winter is 10-30 cm(Zhang and Chen2002).In early November

5472009 , two typical plots representing the growth environment and distribution features were sampled in

548 areas where the sixspecies were distributed, one a dune and the other a plain. In the dune plots, 10 small

549 quadrats $(10 \times 10 \mathrm{~m})$ at right angles to the dune were established by the method of continuous sampling.

550 In the plain, two horizontal transects $1 \mathrm{~km}$ apart were laid out and along the transect eight quadrats (10 $551 \times 10 \mathrm{~m})$ were established at 1-km intervals.

552 Six annual species for weren the 553 study:Erodiumoxyrrhynchum,Trigonellaarcuata,Malcolmiascorpioides,Tetracmerecurvata,Lappulasem 554 iglabra,and Plantagominuta.These species were selected because they are among the most abundant 555 species and are widely distributed in the Gurbantunggut Desert. Furthermore, experimental studies have 556 indicated the importance of generalized competition for seedling survival of these six species.

557 Before snow in early November 2009, the germinating plants in every quadrat were marked. The 558 surviving autumn-germinating together with the spring-germinating plants in the quadrats were counted 559 in early April 2010. At the beginning of June, the numbers of spring- and autumn-germinating plants 560 with fruits, the proportion of autumn and spring germination, and the death rates of spring and autumn 561 seedlings in spring were determined. To measure the yield of mature plants, 20 plants germinating in 562 spring and autumn were sampled at the mature stage. The numbers of deciduous seeds were determined 563 on the basis of residual fruits.

564 In early April, when the plant is in the seedling stage, the morphologyof autumn seedlings is larger 565 than that of spring seedlings. The survival advantage of resistant autumn seedlings is greater (Table 1).

566 The seed production (Table 2)and the death rate for spring and autumn germination (Table 3 ) and of the

567 six species were substituted in the model to calculate the autumn-to-spring ratio of seed germination.

568 The survey revealed that (i) in spring, the biomass of autumn-germination plants was 569 significantly greater than that of spring-germination plants (Table 1), indicating a large difference 570 between the autumn- and spring-germination plants with respect to environmental capacity (the 571 maximum density of adult plants supported by the environment); (ii) the seed yield of 
572 autumn-germinating plants was two times that of spring-germinating plants (Table 2); and (iii) thus,

573 when autumn- and spring-germination plants coexist in one community, there are different density

574 dependences(Table 3), meaning that there should be different RYL. The seed yield of

575 autumn-germinating plants was two times that of spring-germinating plants, and, surprisingly, the seed

576 yield of autumn germination for T.arcuata and P.minutawas five times that of spring germination

577 (Table 2).

578

Table1. Biomass differences between spring and autumn seeding in early spring(kg)

\begin{tabular}{|c|c|c|c|c|}
\hline \multirow{2}{*}{ Species } & \multicolumn{2}{|c|}{ Biomass } & \multirow{2}{*}{$t$} & \multirow{2}{*}{$P$ value } \\
\hline & Germinated in spring & Germinated in autumn & & \\
\hline Erodiumoxyrrhynchum & $0.005 \pm 0.001$ & $0.082 \pm 0.008$ & 101.79 & 0.000 \\
\hline Trigonellaarcuata & $0.013 \pm 0.002$ & $0.033 \pm 0.004$ & 19.63 & 0.000 \\
\hline Malcolmiascorpioides & $0.006 \pm 0.001$ & $0.056 \pm 0.007$ & 49.13 & 0.000 \\
\hline Tetracmerecurvata & $0.031 \pm 0.001$ & $0.027 \pm 0.005$ & 19.85 & 0.000 \\
\hline Lappulasemiglabra & $0.010 \pm 0.002$ & $0.060 \pm 0.010$ & 23.76 & 0.000 \\
\hline Plantagominuta & $0.011 \pm 0.002$ & $0.057 \pm 0.007$ & 41.06 & 0.000 \\
\hline
\end{tabular}

579

580 Table 2. Numbers of seeds produced by plants germinated in autumn $\left(H_{s}\right)$ and spring $\left(H_{f}\right)(\mathrm{Mean} \pm \mathrm{SE})$

\begin{tabular}{llllc}
\hline \multicolumn{1}{c}{ Species } & \multicolumn{1}{c}{$H_{s}$} & \multicolumn{1}{c}{$H_{f}$} & $f$ & $P$ value \\
\hline Erodiumoxyrrhynchum & $86.00 \pm 13.44$ & $291 \pm 25.43$ & 50.91 & 0 \\
Trigonellaarcuata & $3.75 \pm 1.20$ & $22.75 \pm 3.83$ & 22.42 & 0 \\
Malcolmiascorpioides & $1428.75 \pm 242.19$ & $3150.75 \pm 286.13$ & 21.59 & 0 \\
Tetracmerecurvata & $948.00 \pm 153.56$ & $3483.00 \pm 579.28$ & 17.89 & 0 \\
Lappulasemiglabra & $36.80 \pm 4.43$ & $101.45 \pm 17.77$ & 12.46 & 0.001 \\
Plantagominuta & $51.75 \pm 7.66$ & $276.30 \pm 21.94$ & 93.4 & 0 \\
\hline
\end{tabular}

581

582

Table 3 . The mortality rate of autumn seedling $\left(K_{s}\right)$ and spring seedling $\left(K_{f}\right)(\% \pm \mathrm{SE})$

\begin{tabular}{|c|c|c|c|c|}
\hline Species & $K_{\mathrm{s}}$ & $K_{f}$ & $f$ & $P$ value \\
\hline Erodiumoxyrrhynchum & $41.89 \pm 11.96$ & $9.29 \pm 3.51($ In spring $3.20 \pm 1.71)$ & 6.86 & 0.040 \\
\hline Trigonellaarcuata & $56.34 \pm 21.19$ & $35.45 \pm 9.62($ In spring $24.97 \pm 7.75)$ & 0.81 & 0.420 \\
\hline Malcolmiascorpioides & $26.61 \pm 3.89$ & $25.17 \pm 2.74($ In spring $8.28 \pm 0.88)$ & 0.56 & 0.496 \\
\hline Tetracmerecurvata & $62.53 \pm 4.90$ & $25.00 \pm 5.50($ In spring $9.63 \pm 5.00)$ & 24.97 & 0.001 \\
\hline Lappulasemiglabra & $20.01 \pm 2.80$ & $24.70 \pm 8.68($ In spring $6.66 \pm 2.03)$ & 0.26 & 0.634 \\
\hline Plantagominuta & $15.47 \pm 5.39$ & $29.23 \pm 3.66$ (In spring $9.05 \pm 1.74$ & 4.46 & 0.102 \\
\hline
\end{tabular}

583 